\title{
PERAN BARISAN ANSOR SERBAGUNA (BANSER) DALAM MENANGKAL RADIKALISME KEAGAMAAAN DI INDONESIA
}

\author{
Arik Dwijayanto ${ }^{1}$ \\ ${ }^{1}$ Institut Agama Islam Sunan Giri (INSURI) Ponorogo, arikdj99@gmail.com
}

\begin{abstract}
Religious radicalism in several regions has shown a critical condition and tends to present takfirism to the other group's religious beliefs. This encourages the Youth Movement of Nahdlatul Ulama (Ansor-Banser) to play an important role in mainstreaming moderate Islam and religious tolerance. Among the research questions asked are how the role of Ansor-Banser in countering religious radicalism?; and how the concept and strategy of Ansor-Banser in mainstreaming moderate Islam in Indonesia.?By using sosiological theory and historical approach, the findings of this research show that Ansor-Banser has three important roles in countering religious radicalism. Firstly, the role in maintaining security and public order with the government apparatus in particular at religious ceremony both organized by muslim community and non muslim. Secondly, the role in reviewing and monitoring the activities of individuals or groups of radical religious dissemination. Thirdly, the role in educating moderate religious values on the younger generation through training activities. Therefore, this research also aims to be a reference in formulating strategic steps for stakeholders especially muslim youth organization to maintain moderate religious understanding and forming religious behavior by relying on Islamic values of tasamuh, tawasuth and tawazun.
\end{abstract}

Keywords: Deradicalization, Religious radicalism, Ansor-Banser

\begin{abstract}
Abstrak: Fenomena intoleransi yang bermuara dari radikalisme keagamaan di pelbagai wilayah telah menunjukkan suatu kondisi yang mengkhawatirkan. Radikalisme keagamaan yang menguat cenderung menghadirkan pemikiran dan tindakan yang sewenang-wenang terhadap paham keagamaan kelompok lain. Hal ini mendorong Barisan Ansor Serbaguna (Banser) Nahdlatul Ulama untuk memainkan peran dalam mengawal keragaman dan keberagamaan yang toleran serta menjaga persatuan diantara sesama saudara sebangsa (ukhuwah wathaniyah). Penelitian ini dijalankan untuk mengeksplorasi peran dan kontribusi Banser dalam menangkal radikalisasi keagamaan. Penelitian ini menggunakan metode kualitatif dengan pendekatan historis-sosiologis untuk menyingkap lipatan sejarah perjalanan Banser dalam menyikapi paham keagamaan yang radikal. Hasil penelitian ini menunjukkan gambaran bahwa Banser memiliki tiga peran penting dalam menangkal radikalisme keagamaan. Pertama, peran dalam menjaga keamanan dan ketertiban masyarakat bersama aparat pemerintah khususnya pada upacara keagamaan baik yang diselenggarakan oleh komunitas muslim maupun non muslim. Kedua, peran dalam mengkaji dan memantau aktivitas individu atau kelompok penebar paham keagamaan radikal baik di media sosial maupun di ranah gerakan praksis kultural. Ketiga, peran dalam penanaman nilai-nilai keagamaan yang moderat pada generasi muda melalui serangkaian pendidikan dan pelatihan. Dari penelitian ini diharapkan dapat menjadi rujukan dalam merumuskan langkah-langkah strategis bagi semua pihak (stakeholders) khususnya organisasi kepemudaan untuk konsisten menjaga pemahaman keagamaan masyarakat yang moderat serta membentuk perilaku relijius dengan tetap bersandar pada nilai-nilai Islam yang tasamuh, tawasuth dan tawazun.
\end{abstract}

Kata Kunci: Deradikalisasi, Radikalisme Agama, Barisan Ansor Serbaguna 


\section{FARABI}

Jurnal Pemikiran Konstruktif Bidang Filsafat dan Dakwah

ISSN $1907-0993$

E ISSN $2442-8264$

Vol. 16 No. 2, Desember 2019

\section{A. PENDAHULUAN}

Deradikalisasi agama merupakan penanganan kontra radikal atau anti radikal terhadap permasalahan yang muncul dari agama, dalam konteks ini agama yang dimaksud adalah Islam. ${ }^{1}$ Penanganan kontra radikal menjadi gerakan sistemik dan masif dari berbagai stake holder yang menolak kehadiran kelompok radikal khususnya dalam hal keagamaan. Fenomena radikalisme agama yang seringkali muncul dengan narasi kekerasan dan pemaksaan kehendak terhadap kelompok lain bertitik tolak dari adanya pemahaman dan sikap yang bersifat formal dalam menjalankan agama. Benih-benih radikalisme agama yang muncul dari model pemahaman dan sikap keberagamaan secara formalis ini menjadi acuan kelompok Islam tertentu untuk merancang ideologi dan sistem politik melalui formalitas agama. ${ }^{2}$

Formalitas agama ini kemudian diterjemahkan menjadi gerakan dengan agenda utama perubahan terhadap tatanan negara sebagaimana yang dikehendaki para penganut kelompok radikal sehingga justru pada tataran praksis menyebabkan benturan dan konflik. Penyebutan "radikal" dialamatkan terhadap individu atau kelompok yang memiliki karakteristik pemikiran dan gerakan yang menghendaki ditegakkannya syari'at Islam secara kaffah dengan cara-cara yang tidak dibenarkan. Secara terminologi terdapat tiga karakteristik radikalisme

\footnotetext{
${ }^{1}$ Deradikalisasi agama juga dimaknai sebagai proses untuk meluruskan pemahaman keagamaan yang sempit, mendasar menjadi luas, moderat, dan komprehensif. Baca Amirsyah, Meluruskan Salah Faham Terhadap Deradikalisasi: Pemikiran, Konsep, dan Strategi Pelaksanaan, Jakarta: Grafindo Hazanah Ilmu, 2012, 25-35. Secara yuridis, tindakan penanganan radikalisasi atau deradikalisasi mendapat legitimasi dengan didasarkan pada UUD 1945. Dalam Undang-undang tersebut, khususnya pada pasal 28 e ayat 1 disebutkan: "Setiap orang berhak memeluk agama dan beribadah menurut agamanya, memilih pendidikan dan pengajaran, memilih pekerjaan, memilih kewarganegaraan, memilih tinggal di wilayah Negara dan meninggalkannya, serta berhak untuk kembali”. Eddie Siregar, Undang-Undang Dasar Negara Republik Indonesia Tahun 1945, Jakarta: MPR RI, 2012, 67-68. Secara lebih luas, deradikalisasi merupakan segala upaya untuk menetralisir paham-paham radikal melalui pelbagai pendekatan seperti, hukum, psikologi, agama dan juga sosial budaya yang dipengaruhi paham radikal. Lebih lanjut lihat Petrus Reindhard Golose, Deradikalisasi Terorisme, Humanis, Soul Approach dan Menyentuh Akar Rumput, Jakarta: Yayasan Pengembangan Kajian Ilmu Kepolisian, 2009, 23.

${ }^{2}$ Ubaidillah Achmad, "Islam Formalis Versus Islam Lokalis: Studi Pribumisasi Islam Walisongo dan Kiai Ciganjur”, Jurnal ADDIN, Vol. 10, No. 1, Februari 2016, 242.
} 


\section{FARABI}

Jurnal Pemikiran Konstruktif Bidang Filsafat dan Dakwah

ISSN $1907-0993$

E ISSN $2442-8264$

Vol. 16 No. 2, Desember 2019

sebagaimana disebutkan oleh Horace M. Kallen. Pertama, radikalisasi muncul sebagai respon dalam bentuk evaluasi, penolakan, dan perlawanan terhadap suatu kondisi yang sedang berlangsung, umumnya masalah-masalah yang ditolak itu berupa asumsi, ide, lembaga, bahkan tatanan negara yang dianggap tidak sesuai dengan pemikiran Islam radikal. ${ }^{3}$ Kedua, radikalisasi selalu berupaya menggantikan tatanan yang sudah ada dengan sebuah tatanan baru menurut pandangan dan pemikiran mereka sendiri. Para penganut Islam radikal sendiri biasanya selalu berusaha agar tatanan yang sudah ada bisa digantikan oleh tatanan yang sesuai dengan pemikiran mereka ${ }^{4}$. Ketiga, kuatnya keyakinan akan ideologi yang mereka tawarkan, hal tersebut mengakibatkan munculnya sifat emosional yang mengakibatkan kekerasan. ${ }^{5}$

Dalam konteks keberagamaan modern, tidak dapat dipungkiri bahwa sikap fanatik, intoleran, eksklusif dianggap sebagai pemicu radikalisme agama. Di Indonesia, fenomena radikalisme agama di Indonesia tidak hanya menguat pada tataran pemahaman tetapi juga pada tataran aksi. ${ }^{6}$ Bahkan secara terang-terangan

\footnotetext{
${ }^{3}$ Islam radikal merupakan sebuah komunitas yang disorot oleh semua kalangan baik muslim maupun non muslim, karena aktivitas yang sering dilakukan oleh penganut paham Islam radikal sering menimbulkan pro dan kontra, tindakan keras yang dijadikan alasan sebagai jihad merupakan ciri khas dari gerakan Islam Radikal. Hal seperti itu mengakibatkan Islam di Indonesia terpetakan menjadi dua bagian yakni, Islam kanan dan Islam kiri, komunitas radikal disebut sebagai Islam kanan karena dinilai mereka telah sesuai syari'at Islam yang sebenarnya, meskipun sebenarnya image negatif justru sangat melekat pada penganut paham Islam radikal. Umam dan Ahmad Khairul, Pesantren Mencetak Kader-kader Teroris?, Majalah Justisia, 2003, 59.

${ }^{4}$ Revolusi Iran pada tahun 1979 juga sering dijadikan sebagai suatu alasan radikalisme di kalangan beberapa organisasi Islam mengingat pada peristiwa tersebut kelompok Islam berhasil menjadikan syari'at sebagai simbol untuk menggulingkan pemerintah yang sedang berkuasa pada masa itu, dan menjadikan tonggak berdirinya negara Islam. Mereka beranggapan bahwa syari'at Islam merupakan satu-satunya konsep yang baik untuk dijadikan sebuah landasan negara. Dengan berdirinya negara Islam otomatis syari'at Islam akan menjadi dasar landasan dari sebuah negara tersebut, bahkan termasuk sistem politik. Zalda Khamami, Pergulatan Ormas-Ormas Islam Garis Keras di Indonesia, Jakarta: Teraju, 2002, 62-63

${ }^{5}$ Beberapa tindakan kelompok Islam yang mengusung platform "Islam kaffah" justru mengundang respon negatif dari masyarakat, misalnya dengan melakukan tindakan kekerasan seperti melakukan teror bom dan perusakan cafe-cafe atau diskotik oleh salah satu ormas terhadap pihak yang dinilai tidak Islami. Umu Sumbullah, Islam Radikal dan Pluralisme Agama: Studi Kontruksi Sosial Aktivis Hizb al-Tahrir dan Majelis Mujahidin di Malang tentang Agama Kristen dan Yahudi, Jakarta: BALITKAN RI, 2010, 42-43; 109-110.

${ }^{6}$ Secara umum, radikalisme mencakup dua kategori, yakni radikal dalam tataran paham keagamaan dan radikal dalam tataran aksi. Pertama, radikal dalam pemahaman. Pemahaman yang dimaksud di sini adalah pemahaman terhadap ajaran agama yang dianutnya. Jadi para penganut agama memahami dan mengamalkan ajaran agamanya secara literal apa adanya tanpa
} 


\section{FARABI}

Jurnal Pemikiran Konstruktif Bidang Filsafat dan Dakwah

ISSN $1907-0993$

E ISSN $2442-8264$

Vol. 16 No. 2, Desember 2019

atas nama agama, aksi kekerasan dijalankan terhadap kelompok yang berseberangan paham. Kekerasan yang tidak hanya mengarah pada organ fisik tetapi juga upaya pemaksaan kehendak dan paham yang kemudian memunculkan takfirisme atau pelabelan kafir bagi kelompok lain. Hal ini membangkitkan kelompok militan moderat untuk mengambil peran dalam mencegah dan melawan tindakan yang dilakukan kelompok militan radikal. Salah satu kelompok yang mengambil peran untuk menangkal radikalisme keagamaan dijalankan oleh Barisan Ansor Serbaguna (Banser) sebagai organisasi paramiliter Nahdlatul Ulama dalam mengawal dan menjaga moderasi Islam di Indonesia.

\section{B. SEJARAH PERJUANGAN BANSER MELAWAN RADIKALISME}

Sejarah lahirnya Barisan Ansor Serbaguna (Banser) menjadi bagian yang tidak dapat dipisahkan dari sejarah panjang berdirinya Gerakan Pemuda Ansor dan Nahdlatul Ulama. Sebelum berdirinya Barisan Ansor Serbaguna (Banser) Nahdlatul Ulama, lebih dulu muncul organisasi kepemudaan, Nahdlatul Syubban pimpinan Thohir Bahri dan Syubbanul Wathon pimpinan Abdullah Ubaid. Pada tahun 1931, Abdullah Ubaid menghimbau pada pemuda binaannya agar menyatu dalam satu wadah yaitu barisan pemuda NU. Himbauan itu disambut hangat oleh Nahdlatul Syubban dan beberapa organisasi lokal yang banyak berdiri di

memberikan interpretasi atau hasil ijtihad para salafusshalih yang cukup. Misalnya berkaitan dengan penafsiran konsep jihad oleh kelompok Islam radikal yang memaknainya dengan perang sehingga mengakibatkan munculnya pandangan bahwa negara non muslim harus diperangi. Kedua, radikal dalam bentuk aksi. Pada tataran ini merupakan bentuk pengejawantahan dari model yang pertama. Aksi yang dalam konteks ini adalah gerakan frontal, melawan dan bahkan ingin menghancurkan sistem atau tatanan pemerintahan, sosial dan masyarakat bahkan agama, yang semunya itu dianggap tidak sesuai dengan teks agama (al-Qur'an dan Hadits) yang mereka pahami secara literal. Sehingga aksi kelompok radikal sering disertai dengan bom, teror dan senjata terhadap suatu negara atau golongan tertentu yang selalu saja mereka anggap aksi tersebut sebagai sebuah Jihad. Selain itu, radikalisme juga sebagai bentuk reaksi terhadap modernisasi yang dilakukan negara barat terhadap negara Islam, hal tersebut terlihat dengan adanya penolakan penggunaan terhadap produk dari negara-negara yang mayoritas penduduknya beragama non muslim. Radikalisme juga didorong kondisi sosial ekonomi internasional yang dinilai tidak adil bagi kaum muslimin, kemudian para penganut paham radikal berupaya menolak ketidakadilan ekonomi yang cenderung dikuasai negara-negara yang mayoritas non muslim dengan cara-cara kekerasan. Ali Muhtarom, "Peran Ulama dalam Menangkal Radikalisme Agama di Kabupaten Batang Jawa Tengah”, Jurnal RISTEK, Vol. 1, No.1, November 2016, 32-33. Muhammad Asfar, Islam Lunak, Islam Radikal, Pesantren, Terorisme dan Bom Bali, Surabaya: Pusat Studi Demokrasi dan HAM (PusDeHAM), 2003, 19 


\section{FARABI}

Jurnal Pemikiran Konstruktif Bidang Filsafat dan Dakwah

ISSN $1907-0993$

E ISSN $2442-8264$

Vol. 16 No. 2, Desember 2019

kampung-kampung dalam wilayah Surabaya. Pada tahun 1932 di Surabaya, para pemuda bermusyawarah untuk menyatukan perjuangan dalam satu wadah yang kemudian menjadi penanda sejarah lahirnya Persatuan Pemuda Nahdlatul Ulama (PPNU) dengan pimpinan Abdullah Ubaid. Pada muktamar NU ke-9 di Banyuwangi tepatnya tahun 1934 wadah pemuda NU diberi nama baru Ansor Nahdlatoel Oelama (ANO) dengan pimpinan Thohir Bahri. ${ }^{7}$ Selanjutnya dalam kongres II ANO yang berlangsung di Malang pada 21-24 Maret 1937 dibentuklah BANOE (Barisan Ansor Nahdlatoel Oelama) yang kelak menjadi Barisan Ansor Serbaguna (Banser). ${ }^{8}$

Bila dilihat dari sejarah berdirinya Barisan Ansor Serbaguna (Banser), pada awalnya ditujukan sebagai sarana untuk melakukan berbagai kegiatan dalam rangka menjaga ajaran Islam Ahlusunnah Wal Jamaah. Kiprah tersebut dimanifestasikan dalam upaya mempertahankan kemerdekaan Indonesia melalui Resolusi Jihad. Pada masa awal kemerdekaan, Barisan Ansor Serbaguna (Banser) merupakan pengobar semangat perjuangan ditandai dengan berdirinya organisasi semi militer NU, Hizbullah. ${ }^{9}$ Pembentukan Hizbullah ini dipublikasikan dalam

\footnotetext{
${ }^{7}$ Perubahan nama dari Persatuan Pemuda Nahdlatul Ulama menjadi Ansor Nahdlatoel Oelama (ANO) merujuk pada keteladanan kalangan Ansor di Madinah yang menjadi pembela utama Nabi Muhammad SAW dalam perjuangan membela dan menegakkan agama Allah. Dengan demikian, ANO dimaksudkan dapat mengambil hikmah serta teladan dari sikap, perilaku, dan semangat perjuangan para sahabat Nabi yang mendapat predikat Ansor tersebut. Gerakan ANO (yang kelak disebut GP Ansor) senantiasa mengacu pada nilai-nilai dasar 'Sahabat Ansor', yakni sebagai penolong, pejuang, dan pelopor dalam menyiarkan, menegakkan, dan membentengi ajaran Islam. Inilah komitmen awal yang harus dipegang teguh setiap anggota ANO (GP Ansor). Choirul Anam, Pertumbuhan dan Perkembangan Nahdlotul Ulama, Surabaya: AULA, 1990, 93. Lihat juga Saudah Warso, "Gerakan Pemuda Ansor Jawa Timur dalam Penumpasan Sisa-Sisa PKI Tahun 1967 di Blitar Selatan”, Skripsi, IAIN Surabaya 1996, 14.

${ }^{8}$ Berdasar petunjuk KH Hasyim Asyari, materi pengkaderan di Barisan Ansor Nahdlatoel Oelama (BANOE) pada waktu itu berorientasi pada kegiatan di lapangan seperti baris-berbaris, angkat besi, pacuan kuda, melempar lembing, lompat dan lari serta kegiatan sejenisnya sebagaimana keputusan Muktamar NU ke-13 di Menes, Banten pada 1938. Lihat Zainul Milal Bizawie, Laskar Ulama-Santri dan Resolusi Jihad: Garda Depan Menegakkan Indonesia 19451949, Tangerang: Pustaka Compass, 2014, 147.

${ }^{9}$ Sebelumnya Jepang melalui pejabat di Jawa meminta KH Wahid Hasyim untuk membantu dalam pengerahan tenaga muda untuk masuk di Heiho namun ditolak dan mengajukan usulan agar kalangan muda santri dididik dan dilatih dalam wadah kemiliteran sukarela dengan tujuan pembelaan dalam negeri. Pertimbangan KH Wahid Hasyim dengan tujuan pembelaan dalam negeri lebih menarik minat yang besar kalangan muda Islam jika dibandingkan dengan diminta masuk ke Heiho yang lingkup tugasnya adalah membantu pasukan Jepang di front pertempuran diluar wilayah Indonesia. Pemerintah militer Jepang memahami argumentasi KH Wahid Hasyim sehingga memenuhi permintaan kalangan Islam dengan membentuk barisan pertahanan dan
} 


\section{FARABI}

Jurnal Pemikiran Konstruktif Bidang Filsafat dan Dakwah

ISSN $1907-0993$

E ISSN $2442-8264$

Vol. 16 No. 2, Desember 2019

majalah Suara Muslimin Indonesia dan tindakan lanjutan dari KH Wahid Hasyim selaku wakil ketua Masyumi dengan menggelar rapat membicarakan keputusan Jepang terhadap pembentukan kesatuan sukarela dari kalangan Islam di Taman Raden Saleh, Jakarta pada 13-14 September 1944. Sebulan kemudian tepatnya pada 12 Oktober 1944, Masyumi mengadakan rapat khusus dengan mengajukan kesepakatan untuk mengajukan resolusi kepada Jepang agar segera mempersiapkan umat Islam Indonesia untuk siap menerima kemerdekaan Indonesia. $^{10}$

Peran Banser terus berlanjut pada kurun waktu berikutnya. Pada masa pemerintahan Presiden Sukarno, Banser yang terdiri dari anggota-anggota Ansor pilihan dikenal sebagai RPKAD (Resimen Pasukan Komando Angkatan Darat) atau pasukan elitnya NU. Hal ini tidak berlebihan mengingat Banser pada masa itu mendapat latihan istimewa langsung dari RPKAD. Sehingga Banser menjadi mitra TNI dalam menghadapi Nekolim dan kaum kontra revolusi didalam negeri serta segala macam kelompok perongrong negara dan persatuan bangsa. Sejak berdirinya Negara Kesatuan Republik Indonesia (NKRI), Banser meneguhkan diri untuk setia membela Pancasila dan agama. ${ }^{11}$ Pada masa berakhirnya Orde Lama sebelum munculnya Gerakan 30 September, Banser juga pernah menghadapi fitnah besar ketika anggota PKI memalsu stempel GP Ansor dari salah satu

pembelaan tanah air dalam wujud Hizbullah. KH Wahid Hasyim kemudian meminta tokoh NU, Syaifudin Zuhri untuk menyebarkan keputusan Jepang ini kepada pesantren-pesantren di Jawa dan Madura. Ibid., 137.

${ }^{10}$ Sebagai tindak lanjut dari rencana pendidikan dan pelatihan bagi anggota Hizbullah maka setiap pesantren diminta mengirimkan lima santri untuk menjalani diklat di Cibarusa, Bogor, Jawa Barat selama enam bulan dibawah komando pengawasan Kapten Yanagawa yang pernah menjadi pimpinan latihan militer Peta. Hizbullah secara khusus beranggotakan pemuda-pemuda Islam seJawa dan Madura. Pada latihan pertama di Cibarusa, Bogor diklat diikuti 500 pemuda muslim diantaranya Kyai Mustofa Kamil Banten, Kyai Mawardi Solo, Kyai Zarkasi Ponorogo, Kyai Mursyid Pacitan, Kyai Syahid Kediri, Kyai Abdul Halim Majalengka, Kyai Thohir Dasuki Surakarta, Kyai Rojiun Jakarta, Kyai Munasir Ali Mojokerto, Kyai Abdullah , Kyai Wahib Wahab Jombang, Kyai Hasyim Lathif Surabaya, Kyai Zainudin Besuki, Sulthan Fajar Jember dan Kyai Abdullah Abbas Cirebon. Secara ideologis, tujuan dibentuknya Hizbullah adalah untuk menjunjung tinggi perintah agama, menginsyafkan seluruh umat Islam sefrta berusaha meningkatkan upaya dan membulatkan segenap tenaga untuk berjuang dengan semboyan "Luhur bersama-sama dan lebur bersama-sama di jalan Allah untuk menghancurkan musuh yang zalim yakni Amerika Serikat dan Belanda. Barisan pembela tanah air dari kalangan santri (Hizbullah) berdiri pada 14 Oktober 1944 yang keberadaannya memberikan peluang untuk mengatur langkah mencapai kemerdekaan. Ibid., 139.

${ }^{11}$ Panitya Penjusun, Buku Kenangan Harlah 40 Tahun NU (1926-1966), Surabaya: PD Grafika Karja, 1966, 5; 32. 


\section{FARABI}

Jurnal Pemikiran Konstruktif Bidang Filsafat dan Dakwah

ISSN $1907-0993$

E ISSN $2442-8264$

Vol. 16 No. 2, Desember 2019

pengurus ranting Ansor di Surabaya dengan membuat propaganda seolah-olah GP.Ansor akan membentuk Negara Islam Indonesia. Namun hal tersebut mendapat bantahan keras dari Rois Syuriah NU Jawa Timur, KH Machrus Aly dengan menyatakan bahwa desas-desus tersebut merupakan perang urat-syaraf yang dipropagandakan oleh Nekolim dan PKI beserta antek-anteknya. Dalam pernyataannya, KH Machrus Aly menegaskan bahwa Nahdlatul Ulama (termasuk Gerakan Pemuda Ansor) tidak ada impian apalagi niatan untuk membentuk negara Islam seperti yang didesas-desuskan oleh Nekolim dan PKI. NU akan tetap mempertahankan Negara Pancasila sampai akhir zaman. ${ }^{12}$

Pada masa peralihan Orde Lama ke Orde Baru, Barisan Ansor Serbaguna (Banser) juga berdiri di garda terdepan dalam menghadang aksi para kader komunis (PKI). Di Jawa Timur misalnya, aksi sepihak PKI dapat digagalkan Banser. Meskipun dalam Peristiwa Banyuwangi menelan korban 40 anggota gugur melawan pasukan PKI yang rata-rata dipersenjatai. Pertempuran berdarah dengan barisan militan PKI terus berlangsung di semua daerah di Jawa Timur. Pada tahun 1961, GP. Ansor Jawa Timur di bawah pimpinan Hizbullah Huda, mengadakan konsolidasi organisasi secara intensif sampai dengan tahun 1963 dengan menetapkan kebijakan seluruh Ranting Ansor harus memiliki satuan komando Banser. Begitu juga penumpasan PKI di Blitar, kerjasama TNI dan Banser terjalin melalui operasi Trisula. Kapten Hambali dari Kodim Blitar meminta Kayubi selaku Komandan Banser sekaligus Komda GP Ansor agar bersedia membantu Operasi Trisula di wilayah Blitar Selatan. Kapten Hambali melibatkan anggota Banser dalam operasi Trisula mengingat peran dan pengabdiannya tidak diragukan lagi pada Pancasila dan NKRI. Menyikapi permintaan Kapten Hambali, Kayubi segera memberangkatkan anggota-anggota Banser ke gunung batu di selatan sungai Brantas, di wilayah Blitar Selatan untuk menumpas barisan militan PKI. ${ }^{13}$

\footnotetext{
${ }^{12}$ Ibid., 24; 35.

${ }^{13}$ Mengenai keterlibatan Banser dalam penumpasan sisa-sisa kader PKI khususnya di Blitar Selatan pada tahun 1967 dapat dilihat dari beberapa rujukan diantaranya Vannessa Hearman, "Guerrillas, Guns, and Knives? Debating Insurgency in South Blitar, East Java, 1967-68", Source: Indonesia, No. 89 (April 2010), Southeast Asia Program Publications at Cornell University, 66, Agus Sunyoto et al., Banser Berjihad Menumpas PKI, Tulungagung: Lembaga Kajian dan
} 


\section{FARABI}

Jurnal Pemikiran Konstruktif Bidang Filsafat dan Dakwah

ISSN $1907-0993$

E ISSN $2442-8264$

Vol. 16 No. 2, Desember 2019

Hubungan Banser dengan TNI yang kemudian berganti menjadi ABRI berlanjut pada masa Orde Baru. Antara ABRI dan Banser memiliki hubungan kerjasama semakin kuat dan harmonis. Salah satunya ditandai dengan pertemuan resmi antara Pangdam VIII Brawijaya dengan NU, Ansor termasuk Banser pada 25 April 1969 untuk membahas situasi dan kondisi keamanan di Jawa Timur seusai penumpasan sisa-sisa PKI. ${ }^{14}$ Dalam perjalanan berikutnya sinergitas AnsorBanser dengan ABRI dituangkan melalui Deklarasi Semarang 1981 yang menyatakan bahwa Ansor-Banser mempersempit jarak pemisah yang ada hubungannya dengan alat-alat negara baik ABRI maupun instansi Pemerintah. ${ }^{15}$ Dengan demikian eratnya hubungan antara Banser dan TNI pada saat ini tidak lepas dari perjalanan sejarah dalam menjalankan rukun bernegara dan melawan segala bentuk ancaman radikalisme. Begitu juga pada masa Reformasi, Barisan Ansor Serbaguna (Banser) giat berperan di berbagai gerakan sosial keagamaan. ${ }^{16}$

\section{PERAN BANSER DALAM DERADIKALISASI KEAGAMAAN}

Semenjak menguatnya pemikiran keagamaan kelompok Islam radikal di Indonesia, hubungan komunitas masyarakat muslim di beberapa wilayah menjadi kurang harmonis bahkan cenderung berhadap-hadapan. Hal ini disebabkan cara pandang kelompok keagamaan radikal yang tidak akomodatif dalam bersentuhan dengan tradisi-tradisi lokal masyarakat yang justru semakin mempertegas jarak sosial dan batas-batas budaya tiap-tiap kelompok sehingga akibatnya relasi yang terbangun cenderung relasi konflik. Radikalisme keagamaan cenderung

Pengembangan PW GP Ansor Jawa Timur \& Pesulukan Thoriqoh Agung, 1996, 161-80. Saudah Warso, "Gerakan Pemuda Ansor Jawa Timur dalam Penumpasan Sisa-Sisa PKI Tahun 1967 di Blitar Selatan”, Skripsi, IAIN Surabaya, 1996, 62-74 dan beberapa peristiwa lokal juga terangkum dalam portal http://gp-ansor.weebly.com/ diakses 06 Juni 2017.

${ }^{14}$ Choirul Anam, Gerak Langkah Pemuda Ansor: Sebuah Percikan Sejarah Kelahiran, Surabaya: PN Aula, 1990, 96. Saudah Warso, Gerakan Pemuda Ansor Jawa Timur, 27-28.

${ }^{15}$ Hasil Kongres Semarang, PP GP Ansor 1981, 19 sebagaimana dikutip Saudah Warso, Gerakan Pemuda Ansor Jawa Timur, 26.

${ }^{16}$ Harian Republika, Jumat, 14 Januari 2011, 25 


\section{FARABI}

Jurnal Pemikiran Konstruktif Bidang Filsafat dan Dakwah

ISSN $1907-0993$

E ISSN $2442-8264$

Vol. 16 No. 2, Desember 2019

menghadirkan pemikiran dan tindakan yang sewenang-wenang terhadap paham keagamaan kelompok lain. ${ }^{17}$

Hal tersebut memicu terjadinya penentangan oleh beberapa kelompok masyarakat yang melakukan kontra radikalisme sebagaimana kumpulan organisasi yang tergabung dalam Aliansi Masyarakat Anti Radikalisme (AMAR) Ponorogo pada hari Kamis tanggal 29 September 2011 melakukan demonstrasi di pusat kota menentang radikalisme agama yang muncul di wilayah tersebut. Aksi deradikalisasi yang dilakukan GP Ansor, Banser, PMII, IPNU dan IPPNU menentang propaganda atas ajaran Majelis Tafsir al-Qur'an (MTA) yang dianggap telah memicu perpecahan umat melalui siaran radionya. Dalam tuntutannya AMAR juga mendesak kepada pemerintah daerah dan aparat kepolisian agar bertindak tegas terhadap setiap aktivitas individu maupun kelompok yang mencoba menyebarkan paham Islam radikal melalui lembaga pendidikan formal maupun non formal, serta jaringan media massa. Protes massal yang dilakukan Ansor, Banser, PMII dan IPNU/IPPNU merupakan respons terbuka yang dilakukan secara masif atas aktivitas radio Majelis Tafsir Al Quran (MTA) yang dinilai menyebarkan ajaran yang dinilai berseberangan dengan kelompok Nahdliyin. Keberadaan serta program siar Radio MTA yang berdiri selama beberapa bulan di Ponorogo telah beberapa kali memicu protes dari masyarakat khususnya kalangan Nahdliyin karena aktivitas siaran Radio MTA bertentangan dengan ajaran agama Islam Ahlusunnah Wal Jamaah yang dianggap MTA sebagai ajaran bid'ah. ${ }^{18}$

Maraknya intoleransi dan radikalisme agama juga memaksa barisan militan moderat (Banser) turun gunung memerangi pengaruh kaum ultra konservatif Islam. Banser menempatkan diri di garda terdepan dalam perang melawan intoleransi dan radikalisme agama. Beberapa kali GP Ansor dan Banser melakukan aksi penentangan terhadap kelompok yang memicu munculnya

\footnotetext{
${ }^{17}$ Arik Dwijayanto dan Dawam Multazamy Rohmatuloh, "Muslim Ponoragan: Relasi Agama dan Budaya dalam Masyarakat Islam di Ponorogo Abad XX", Penelitian, LP2M IAI Sunan Giri Ponorogo, 2016, 85.

18 "Ribuan Warga Nahdliyin Demo Radio Majelis Tafsir Al-Quran", dalam http://www.antarajatim.com/lihat/berita/72725/ribuan-warga-nahdliyin-demo-radio-majelis-tafsiral-quran diakses 17 Juli 2017.
} 


\section{FARABI}

Jurnal Pemikiran Konstruktif Bidang Filsafat dan Dakwah

ISSN $1907-0993$

E ISSN $2442-8264$

Vol. 16 No. 2, Desember 2019

radikalime agama. Salah satunya di Semarang yang dijadikan lokasi pertemuan Hizbut Tahrir Indonesia (HTI), Banser mengepung gedung dan mendesak penyelenggara acara membubarkan Forum Khilafah tersebut. Keberagamaan di Indonesia yang semakin tergerus dampak dari gelombang radikalisme agama menuntut Barisan Ansor Serbaguna (Banser) yang kini beranggotakan dua juta orang mengambil peran terhadap aktivitas kelompok radikal. ${ }^{19}$

Begitu juga di Makassar, aksi massa HTI yang sering mengkampanyekan khilafah bersikeras melakukan kegiatan tablig akbar pada Ahad, 16 April 2017 sehingga memantik keributan. Ketika anggota HTI melakukan orasi, anggota Banser mencoba menghadang yang juga diikuti oleh anggota Pergerakan Mahasiswa Islam Indonesia (PMII). Namun kelompok HTI melakukan perlawanan dengan mengacungkan bambu yang terikat bendera sehingga terjadi aksi saling dorong dan kondisi semakin memanas ketika massa HTI tetap mempertahankan umbul-umbul Islam dan berteriak khilafah. Bentrok fisik akhirnya berhasil diredam setelah kedua komandan dari kedua ormas menarik massanya masing-masing. Ketua Gerakan Pemuda Ansor Sulawesi Selatan, Muhammad Tonang menyatakan bahwa sejak awal kegiatan HTI bertentangan dengan ideologi Pancasila sehingga ia menegaskan tidak membenarkan HTI menggelar tablig akbar. Apalagi menurutnya Pemerintah Kota Makassar dan kepolisian juga tak memberikan izin kegiatan. ${ }^{20}$

Tidak hanya radikalisasi yang dijalankan oleh organisasi atau kelompok, Banser juga mengambil peran untuk mencegah radikalisme yang dilakukan oleh individu sebagaimana peristiwa di Sidoarjo, Jawa Timur yang menuai beragam kontroversi ketika anggota Banser menghentikan pengajian yang dinilai

\footnotetext{
${ }^{19}$ Komandan Satuan Koordinasi Nasional (Kasatkornas) Banser, Alfa Isnaeni menyatakan bahwa Banser akan terus aktif memerangi geliat radikalisme dan memberangus pengaruh kelompok ultra konservatif. Ia menegaskan bahwa pihak yang tidak setuju terhadap NKRI atau menyuarakan kekhalifahan akan berhadapan dengan Banser. Selama ini Banser dikenal bergerak di pengadilan jalanan sedangkan Gerakan Pemuda Ansor meniti jalur dialog untuk membangun konsensus di antara umat Muslim terkait penerapan hukum Islam di era kekinian. Sebagaimana yang dinyatakan Sekretaris Jendral NU, Yahya Cholil Staquf yang meyakini bahwa perang melawan radikalisme agama tidak bisa menunggu konsensus politik. http://www.dw.com/id/kaummilitan-moderat-indonesia-perangi-radikalisme-agama/a-39206404 diakses 17 Juli 2017.

${ }^{20} \mathrm{https} / / /$ nasional.tempo.co/amphtml/read/news/2017/04/16/078866531/ricuh-tablig-akbarmassa-hti-dan-banser-ansor-bentrok-di-makassar diakses 17 Juli 2017.
} 


\section{FARABI}

Jurnal Pemikiran Konstruktif Bidang Filsafat dan Dakwah

ISSN $1907-0993$

E ISSN $2442-8264$

Vol. 16 No. 2, Desember 2019

provokatif dan berpotensi menimbulkan konflik antar umat Islam. Hal tersebut terjadi pada forum pengajian yang menghadirkan penceramah Khalid Basalamah di Masjid Shalahuddin, Perumahan Puri Suya Jaya, Gedangan Sidoarjo pada hari Sabtu, 4 Maret 2017. Rizza Ali Faizin, Ketua GP Ansor Cabang Sidoarjo menyatakan bahwa Ansor dan Banser tidak membenci pengajian, namun tidak sependapat dengan isi pengajian Khalid yang sering mengadu domba antar umat beragama, atau mengajak saling membenci antar umat beragama. GP Ansor dan Banser sebelumnya juga sudah melakukan penolakan melalui surat resmi ke pengurus takmir Masjid Shalahuddin. Menurut Kapolresta Sidoarjo, Kombespol Muhammad Anwar Nasir menyatakan bahwa sudah ada kesepakatan antara pengurus takmir Masjid Shalahuddin dan GP Ansor Cabang Sidoarjo yang kemudian disepakati bahwa penceramah Khalid Basalamah diganti dengan penceramah lainnya namun kenyataannya pada pelaksanaan tetap tidak diganti. Sehingga ketika Khalid Basalamah berceramah, GP Ansor dan Banser meminta Khalid untuk tidak meneruskan ceramahnya. Akhirnya setelah kurang lebih 25 menit berceramah, Khalid mengakhiri ceramahnya. ${ }^{21}$

Peran dan dedikasi para anggota Banser tidak hanya pada pencegahan dan perlawanan terhadap radikalisme agama semata namun juga mengawal toleransi antar umat beragama. Sebagaimana agenda rutin setiap tahun ketika malam Natal anggota Banser diberbagai daerah diminta oleh pihak aparat keamanan dan pihak gereja untuk ikut membantu menjaga ketertiban dan keamanan. Bahkan seorang anggota Banser dari Mojokerto, Riyanto rela kehilangan nyawa ketika bertugas memberikan perlindungan keamanan bagi umat Kristiani di malam Natal akibat ledakan bom di Gereja Eben Haezer, Mojokerto, Jawa Timur, 17 tahun silam. Riyanto, anggota Banser kelahiran Kediri, 23 November 1975 ditemukan meninggal dunia saat mengamankan malam Natal di Mojokerto pada 24 Desember 2000. Bom meledak dan tubuhnya terlempar sejauh lebih dari 100 meter. Sementara, seorang rekannya sesama anggota banser menderita cacat di

21 https://news.detik.com/berita-jawa-timur/d-3438227/ansor-dan-banser-sidoarjo-mintaceramah-khalid-basalamah-dihentikan diakses 17 Juli 2017. 


\section{FARABI}

Jurnal Pemikiran Konstruktif Bidang Filsafat dan Dakwah

ISSN $1907-0993$

E ISSN $2442-8264$

Vol. 16 No. 2, Desember 2019

mata kanannya. Gugurnya Riyanto di medan tugas sebagai contoh nyata kepedulian Banser untuk menjaga keamanan dalam kebhinekaan. ${ }^{22}$

Selain tugas kemanusiaan dalam menjaga toleransi beragama, Banser juga dilibatkan dalam mengamankan wilayah perbatasan dari ancaman radikalisme. Sebagaimana anggota Banser Sulawesi Utara yang ditugaskan ikut berpatroli bersama polisi dan tentara di wilayah perbatasan Indonesia - Filipina, tepatnya di Kabupaten Talaud. Banser yang ikut mengamankan perbatasan bersama Polri dan TNI membawa misi untuk mencegah masuknya ISIS dari Marawi, Filipina Selatan ke Indonesia. Para anggota Banser ditempatkan di tiga pulau terluar, yakni Kepulauan Kawaluso, Kepulauan Matutuang dan Kepulauan Marore. Menurut Komandan Satuan Koordinasi Wilayah (Satkorwil) Banser Sulawesi Utara, Hi Ali Tumiwan menyatakan bahwa sejak tanggal 3 Juni 2017 hingga malam menjelang Hari Raya Idul Fitri, Banser diminta Kapolres Sangihe dan Komandan Kodim 1301 Sangihe-Talaud untuk ikut bersama melakukan pengamanan di perbatasan dari bahaya ISIS. Ketua Pimpinan Wilayah Gerakan Pemuda Ansor Sulawesi Utara, Yusra Alhabsy juga menyatakan bahwa keterlibatan anggota Banser dalam menjaga perbatasan merupakan bukti nyata Ansor dan Banser ikut berada di garis depan untuk memerangi kelompok radikal yang ingin menggerogoti persatuan Indonesia. Menurutnya, sebagaimana perjuangan para ulama untuk menyatukan NKRI, Banser juga berkewajiban menjaga NKRI dari ancaman-ancaman paham yang ingin merusak tatanan NKRI sehingga hal ini memotivasi anggota Banser terlibat langsung menjaga perbatasan dari ancaman masuknya ISIS ke Sulawesi Utara. $^{23}$

Beberapa contoh kasus diatas merupakan sebagian peran dan kontribusi yang dilakukan Barisan Ansor Serbaguna (Banser) untuk menjaga moderasi Islam yang telah lama dibangun oleh para ulama Nusantara. Banser sebagai alat perjuangan ulama (NU) juga memiliki tanggungjawab untuk melanjutkan misi

22 http://regional.liputan6.com/read/2687069/riyanto-anggota-banser-yang-memeluk-bommeledak-di-malam-natal diakses17 Juli 2017.

$23 \mathrm{https} / / /$ nasional.tempo.co/read/news/2017/06/14/078884557/jelang-lebaran-banser-ditarik-dari-perbatasan-indonesiafilipina diakses 17 Juli 2017. 


\section{FARABI}

Jurnal Pemikiran Konstruktif Bidang Filsafat dan Dakwah

ISSN $1907-0993$

E ISSN $2442-8264$

Vol. 16 No. 2, Desember 2019

Islam yang membawa rahmat persatuan bukan perpecahan sebagaimana hadirnya Islam di Indonesia yang santun dan penuh kedamaian.

\section{STRATEGI GERAKAN BANSER MENANGKAL RADIKALISME AGAMA}

Dalam upaya melakukan kontra radikalisme agama, Banser melakukan transformasi dengan membentuk satuan khusus. Secara struktural melalui Gerakan Pemuda Ansor, Detasemen Khusus 99 Barisan Ansor Serba Guna (Densus 99 Banser) dibentuk sebagai salah satu upaya untuk merevitalisasi dan mentransformasi Banser guna membantu kepolisian dalam pencegahan deradikalisasi agama yang masih sering terjadi. Densus 99 Banser yang dibentuk pada 24 April 2011 bertujuan untuk memberikan pencegahan dan edukasi kepada umat Islam khususnya agar tidak terprovokasi atas kelompok yang ingin membubarkan NKRI, merusak Pancasila dan UUD 1945. Densus 99 Banser memiliki 204 personel dan mempunyai kemampuan bela diri serta mempu menjinakkan bom. Tak hanya itu, dalam upaya transformasi Banser, GP Ansor juga membentuk Banser Lalu Lintas (Balalin) yang bertujuan membantu kepolisian dalam mengatur arus lalu lintas, Banser Pemadam Kebakaran (Balakar) untuk membantu petugas pemadam kebakaran dan Banser Tanggap Bencana (Bagana) yang bertujuan untuk membantu masyarakat yang terkena bencana alam. $^{24}$

Densus 99 Banser secara organisatoris tidak memiliki hubungan struktural dengan Densus 88 Anti Teror Polri. Namun pasukan khusus Banser Nahdlatul Ulama (NU) ini memiliki tanggung jawab yang hampir sama, yakni mencegah adanya terorisme dalam segala bentuk. Ketua Umum GP Ansor periode 20112016, Nusron Wahid, menjelaskan bahwa Densus 99 didirikan tepat pada ulang tahun ke-77 GP Ansor pada 24 April 2011. Pembentukannya bertepatan dengan banyaknya radikalisasi yang mengatasnamakan agama sebagaimana peledakan bom dan kekerasan di ruang publik. Densus 99 memiliki tugas khusus dalam

24 http://www.republika.co.id/berita/nasional/umum/11/07/18/logz41-hadapi-kelompokgaris-keras-banser-nu-bentuk-densus-99 diakses 17 Juli 2017. 


\section{FARABI}

Jurnal Pemikiran Konstruktif Bidang Filsafat dan Dakwah

ISSN $1907-0993$

E ISSN $2442-8264$

Vol. 16 No. 2, Desember 2019

melakukan pencegahan terorisme dan memberikan wawasan kepada masyarakat supaya tidak terprovokasi oleh gerakan-gerakan yang menginginkan perpecahan umat di Indonesia. Menurut Nusron dalam apel Banser pada Harlah ke-85 NU di Gelora Bung Karno, Jakarta pada Minggu (17/7/2011), selain melakukan pencegahan, Densus 99 juga melakukan monitoring terhadap segala bentuk tindak kekerasan yang kemudian dikoordinasikan kepada aparat. Nama Densus 99 diambil dari asmaul husna atau nama-nama indah bagi Allah, yang jumlahnya 99. Densus ini kedepan juga akan dilatih juga oleh aparat kepolisian dan dilengkapi kemampuan menjinakkan bom dan kontra intelijen. ${ }^{25}$

Terbentuknya Densus 99 Banser memiliki kontribusi signifikan dalam upaya menangkal radikalisme di Indonesia dan membantu pihak kepolisian. Komandan Densus 99 Banser NU, Nurruzaman mengungkapkan jika peristiwa bom bunuh diri yang terjadi di Kampung Melayu pada bulan Mei 2017 disinyalir kuat merupakan aksi dari Jamaah Ansoru Daulah (JAD). Nurruzaman menduga jika pelaku bom bunuh diri merupakan jaringan Cibiru. Dari informasi yang diperoleh Densus 99 Banser NU, dua terduga pelaku teroris tersebut berasal dari Bandung. Kedua terduga teroris tersebut merupakan jaringan JAD Bandung Barat dan tindak teror bom tersebut terkait dengan instruksi dari ISIS internasional untuk melakukan serangkaian aksi terorisme di beberapa tempat. ${ }^{26}$

Selain membentuk Detasemen Khusus 99 (Densus 99) Banser juga menyiapkan pasukan siber di dunia maya untuk melawan radikalisme. Sebagaimana pernyataan Yaqut Cholil Qoumas, Ketua Umum GP Ansor periode 2015-2020 mendorong anggota Banser tidak hanya melawan radikalisme di dunia nyata, tetapi juga berperan aktif di dunia maya. Menurutnya, perkembangan radikalisme yang memanfaatkan teknologi informasi belakangan ini cukup kuat. Sehingga sebagai upaya dalam menghadapi radikalisme di dunia maya, GP Ansor membentuk tentara siber untuk menggempur kampanye kelompok-kelompok

25 https://news.detik.com/berita/d-1682843/densus-99-pasukan-khusus-banser-nu-untukcegah-terorisme diakses 17 Juli 2017.

${ }^{26} \mathrm{http}$ ///www.tribunnews.com/nasional/2017/05/26/komandan-banser-nu-bongkar-jaringanterorisme-di-indonesia-nama-nama-tokoh-ini-disebut diakses 17 Juli 2017. http://berita.suaramerdeka.com/densus-99-banser-duga-bom-kampung-melayu-terkait-jamaahansoru-daulah/ diakses 17 Juli 2017 


\section{FARABI}

Jurnal Pemikiran Konstruktif Bidang Filsafat dan Dakwah

ISSN $1907-0993$

E ISSN $2442-8264$

Vol. 16 No. 2, Desember 2019

radikal. Selain itu, anggota Banser di seluruh Indonesia yang berjumlah 1,7 juta orang juga telah disiagakan untuk menghadapi ancaman radikalisme dalam bentuk apapun. Senada dengan pernyataan Deputi Bidang Pencegahan, Perlindungan, dan Deradikalisasi Badan Nasional Penanggulangan Terorisme (BNPT), Mayor Jenderal Abdul Rahman Kadir yang menyebut peran dunia maya dan media sosial cukup kuat dalam memengaruhi generasi muda hingga tersangkut dengan gerakan radikal. Ia mengungkapkan bahwa banyak situs berkedok Islam yang isinya ternyata memutarbalikkan fakta. BNPT mencatat hingga saat ini terdapat 15 ribu situs yang berisi paham radikal. ${ }^{27}$

Pasca terbentuknya tentara siber, sebanyak 112 ribu anggota Barisan Ansor Serba Guna (Banser) di Jawa Tengah disiagakan untuk berpatroli di media sosial. Hal ini dilakukan seiring maraknya unggahan provokatif hingga berujung pada penghinaan ulama. Menurut Ketua Pimpinan Wilayah Gerakan Pemuda Ansor Jawa Tengah, Ikhwanuddin pada 30 November 2016 menyatakan bahwa perbedaan pendapat yang dilontarkan berbagai pihak di dunia maya semakin hari semakin memanas dan justru menyulut konflik khususnya sikap netizen yang tanpa kontrol dan etika menghina tokoh agama sehingga patroli di media sosial urgen untuk dilakukan. Hasil inventarisir GP Ansor, kejadian penghinaan ulama marak terjadi. Sejumlah tokoh seperti Buya Syafii Ma'arif, Ketua Umum PBNU KH Said Aqil Siradj, KH Quraish Shihab, KH Mustofa Bisri (Gus Mus), KH Maemun Zubair bahkan menjadi korban. Para ulama itu tak luput dari cacian kecaman netizen di media sosial. Secara khusus, patroli medsos dilakukan dengan melibatkan kader yang mumpuni di bidang informasi dan teknologi (IT). Selain patroli di dunia maya, Banser juga mensiagakan patroli darat dengan berkoordinasi dengan aparat tentang infomasi dan data. Koordinasi itu dilakukan dengan komando pimpinan. Sebelumnya, pasukan Banser juga telah berhasil mendeteksi beberapa pelaku penghina ulama di Jawa Tengah. Para pelaku kemudian diantar untuk meminta maaf dan bertemu langsung ulama tersebut. GP Ansor juga menyatakan sikap dengan mendesak aparat penegak hukum untuk

27 http://nasional.republika.co.id/berita/nasional/umum/16/04/28/o6c5ts365-banser-nusiapkan-ansor-cyber-army diakses 17 Juli 2017. 


\section{FARABI}

Jurnal Pemikiran Konstruktif Bidang Filsafat dan Dakwah

ISSN $1907-0993$

E ISSN $2442-8264$

Vol. 16 No. 2, Desember 2019

memproses pelaku penebar kebencian di jejaring sosial. Proses itu tentunya sesuai dengan Undang-undang nomor 11 tahun 2008 tentang Informasi dan Transaksi Elektronik (ITE). ${ }^{28}$

Selain peran dalam menjaga keamanan bersama aparat pemerintah dan peran dalam memantau aktivitas individu atau kelompok penebar paham keagamaan radikal, Banser juga berperan dalam penanaman nilai-nilai keagamaan yang moderat pada generasi muda melalui serangkaian pendidikan dan pelatihan. Komandan Satuan Koordinasi Wilayah Banser Jawa Timur, Abid Umar pada Kamis, 19 Januari 2017, menyatakan bahwa Banser tidak bisa berdiri sendiri dalam menjaga persatuan dan keutuhan NKRI sehingga Banser menjalin kerja sama dengan semua elemen masyarakat dan para stakeholder dalam setiap kegiatannya termasuk dengan TNI dan Polri. Kerja sama dengan TNI dan Polri terjalin dalam pelatihan-pelatihan berjenjang yang wajib diikuti oleh seluruh anggota Banser. TNI dan Polri dilibatkan dalam pendidikan dan pelatihan kader Banser dalam hal pengembangan wawasan kebangsaan dan pengetahuan militeristik. Bukan hanya wawasan dan pengetahuan, TNI-Polri juga diminta melatih fisik kader Banser dalam kegiatan pendidikan dan pelatihan. Menurut Abid, terdapat tiga jenjang pendidikan wajib yang harus diikuti oleh Banser yakni pendidikan dan latihan dasar (Diklatsar), pendidikan khusus Banser lanjutan (Susbalan), dan pendidikan khusus Banser pimpinan (Susbanpim). Setiap jenjang pendidikan dalam Banser selalu melibatkan TNI-Polri untuk menjadi narasumber maupun instruktur mengingat TNI dan Polri memiliki penguasaan keilmuan tentang pertahanan dan strategi. Meskipun TNI dan Polri dilibatkan dalam pendidikan dan pelatihan Banser, Abid menegaskan bahwa tidak ada nama pejabat dari lingkungan TNI maupun Polri yang menjadi pembina atau posisi apapun dijabatan struktural organisasi, walaupun hubungan antara Banser dengan TNI dan Polri terjalin ikatan yang harmonis sejak puluhan tahun. ${ }^{29}$

${ }^{28}$ http://nasional.news.viva.co.id/news/read/854187-112-ribu-anggota-banser-gelar-patrolidi-media-sosial diakses 17 Juli 2017.

${ }^{29}$ http://www.viva.co.id/indepth/sorot/873249-menelisik-ormas-paramiliter diakses 07 Agustus 2017. 


\section{FARABI}

Jurnal Pemikiran Konstruktif Bidang Filsafat dan Dakwah

ISSN $1907-0993$

E ISSN $2442-8264$

Vol. 16 No. 2, Desember 2019

\section{E. PENUTUP}

"Kita tengah menghadapi orang-orang yang hilang rasa memiliki terhadap NKRI. Mereka ini adalah orang-orang yang kost di negeri ini. Bagi mereka, yang penting adalah cinta agama dan buang jauh-jauh cinta tanah air. Bagaimana kita bisa bersujud menyembah-Nya bila tak punya tanah air? "30

Dalam konteks ini, Banser memiliki peran strategis untuk mengikis berkembangnya paham keagamaan yang tidak sejalan dengan nilai-nilai Pancasila, UUD 1945 dan NKRI. Sudah sangat jelas bahwa sejarah hadirnya Islam di Indonesia tidak memiliki spirit radikalisme atau ekstrimisme. Peneguhan peran Banser menjadi penting sebagai langkah untuk mengawal dan menjaga nilai-nilai Islam yang mengedepankan sikap moderat, toleran dan seimbang. Dengan spirit Resolusi Jihad Hadratus Syaikh Hasyim Asyari, kader-kader Banser harus mampu mengemban misi sebagai penggerak ajaran Islam yang rahmatan lil 'alamin. Akhirnya, berjejak dari fakta historis dan fakta sosial sebagaimana paparan diatas, Barisan Ansor Serbaguna (Banser) memiliki tiga peran penting dalam menangkal radikalisme keagamaan di Indonesia. Pertama, peran dalam menjaga keamanan dan ketertiban masyarakat bersama aparat pemerintah khususnya pada upacara keagamaan baik yang diselenggarakan oleh komunitas muslim maupun non muslim. Kedua, peran dalam mengkaji dan memantau aktivitas individu atau kelompok penebar paham keagamaan radikal baik di media sosial maupun di ranah gerakan praksis kultural. Ketiga, peran dalam penanaman nilai-nilai keagamaan yang moderat pada generasi muda melalui serangkaian pendidikan dan pelatihan.

\footnotetext{
${ }^{30}$ Petikan tulisan Said Agil Siradj yang dimuat harian Kompas yang telah dibukukan Lakpesdam dalam karya kompilasi yang berjudul Nasionalisme dan Islam Nusantara, Jakarta: Gramedia, 2015, 3.
} 


\section{FARABI}

Jurnal Pemikiran Konstruktif Bidang Filsafat dan Dakwah

ISSN $1907-0993$

E ISSN $2442-8264$

Vol. 16 No. 2, Desember 2019

\section{DAFTAR PUSTAKA}

Achmad, Ubaidillah. (2016), "Islam Formalis Versus Islam Lokalis: Studi Pribumisasi Islam Walisongo dan Kiai Ciganjur", Jurnal ADDIN, Vol. 10, No. 1, Februari.

Amirsyah. (2012), Meluruskan Salah Faham Terhadap Deradikalisasi: Pemikiran, Konsep, dan Strategi Pelaksanaan, Jakarta: Grafindo Hazanah Ilmu.

Anam, Choirul. (1990), Pertumbuhan dan Perkembangan Nahdlotul Ulama, Surabaya: PN Aula.

Anam, Choirul. (1990), Gerak Langkah Pemuda Ansor: Sebuah Percikan Sejarah Kelahiran, Surabaya: PN Aula.

Asfar, Muhammad. (2003), Islam Lunak, Islam Radikal, Pesantren, Terorisme dan Bom Bali, Surabaya: Pusat Studi Demokrasi dan HAM (PusDeHAM)

Bizawie, Zainul Milal. (2014), Laskar Ulama-Santri dan Resolusi Jihad: Garda Depan Menegakkan Indonesia 1945-1949, Tangerang: Pustaka Compass

Dwijayanto, Arik dan Dawam Multazamy. (2016), "Muslim Ponoragan: Relasi Agama dan Budaya dalam Masyarakat Islam di Ponorogo Abad XX", Penelitian, LP2M IAI Sunan Giri Ponorogo.

Golose, Petrus Reindhard. (2009), Deradikalisasi Terorisme, Humanis, Soul Approach dan Menyentuh Akar Rumput, Jakarta: Yayasan Pengembangan Kajian Ilmu Kepolisian.

Harian Republika, Jumat, 14 Januari 2011

Hearman, Vannessa. (2010), "Guerrillas, Guns, and Knives? Debating Insurgency in South Blitar, East Java, 1967-68”, Source: Indonesia, No. 89 April, Southeast Asia Program Publications at Cornell University.

Khamami, Zalda. (2002), Pergulatan Ormas-Ormas Islam Garis Keras di Indonesia, Jakarta: Teraju

Lakpesdam. (2015), Nasionalisme dan Islam Nusantara, Jakarta: Gramedia

Panitya Penjusun. (1996), Buku Kenangan Harlah 40 Tahun NU (1926-1966), Surabaya: PD Grafika Karja. 


\section{FARABI}

Jurnal Pemikiran Konstruktif Bidang Filsafat dan Dakwah

ISSN $1907-0993$

E ISSN $2442-8264$

Vol. 16 No. 2, Desember 2019

Muhtarom, Ali. "Peran Ulama dalam Menangkal Radikalisme Agama di Kabupaten Batang Jawa Tengah", Jurnal RISTEK, Vol. 1, No.1, November 2016

Siregar, Eddie. (2012), Undang-Undang Dasar Negara Republik Indonesia Tahun 1945, Jakarta: MPR RI.

Sumbullah, Umu. (2010). Islam Radikal dan Pluralisme Agama: Studi Kontruksi Sosial Aktivis Hizb al-Tahrir dan Majelis Mujahidin di Malang tentang Agama Kristen dan Yahudi, Jakarta: BALITKAN RI.

Sunyoto, Agus et al. (1996), Banser Berjihad Menumpas PKI, Tulungagung: Lembaga Kajian dan Pengembangan PW GP Ansor Jawa Timur \& Pesulukan Thoriqoh Agung.

Umam dan Ahmad Khairul (2003), Pesantren Mencetak Kader-kader Teroris?, Majalah Justisia.

Warso, Saudah. (1996), "Gerakan Pemuda Ansor Jawa Timur dalam Penumpasan Sisa-Sisa PKI Tahun 1967 di Blitar Selatan”, Skripsi, IAIN Surabaya.

\section{Sumber Internet}

http://gp-ansor.weebly.com/ diakses 06 Juni 2017.

http://www.antarajatim.com/lihat/berita/72725/ribuan-warga-nahdliyin-demoradio-majelis-tafsir-al-quran diakses 17 Juli 2017.

http://www.dw.com/id/kaum-militan-moderat-indonesia-perangi-radikalismeagama/a-39206404 diakses 17 Juli 2017.

https://nasional.tempo.co/amphtml/read/news/2017/04/16/078866531/ricuhtablig-akbar-massa-hti-dan-banser-ansor-bentrok-di-makassar diakses 17 Juli 2017.

https://news.detik.com/berita-jawa-timur/d-3438227/ansor-dan-banser-sidoarjominta-ceramah-khalid-basalamah-dihentikan diakses 17 Juli 2017.

http://regional.liputan6.com/read/2687069/riyanto-anggota-banser-yangmemeluk-bom-meledak-di-malam-natal diakses 17 Juli 2017.

https://nasional.tempo.co/read/news/2017/06/14/078884557/jelang-lebaran-banser-ditarik-dari-

perbatasan-indonesia-filipina diakses 17 Juli 2017.

http://www.republika.co.id/berita/nasional/umum/11/07/18/logz41-hadapi-

kelompok-garis-keras-banser-nu-bentuk-densus-99 diakses 17 Juli 2017. 


\section{FARABI}

Jurnal Pemikiran Konstruktif Bidang Filsafat dan Dakwah

ISSN $1907-0993$

E ISSN $2442-8264$

Vol. 16 No. 2, Desember 2019

https://news.detik.com/berita/d-1682843/densus-99-pasukan-khusus-banser-nuuntuk-cegah-terorisme diakses 17 Juli 2017.

http://www.tribunnews.com/nasional/2017/05/26/komandan-banser-nu-bongkarjaringan-terorisme-di-indonesia-nama-nama-tokoh-ini-disebut diakses 17 Juli 2017.

http://berita.suaramerdeka.com/densus-99-banser-duga-bom-kampung-melayuterkait-jamaah-ansoru-daulah/ diakses 17 Juli 2017

http://nasional.republika.co.id/berita/nasional/umum/16/04/28/o6c5ts365-bansernu-siapkan-ansor-cyber-army diakses 17 Juli 2017.

http://nasional.news.viva.co.id/news/read/854187-112-ribu-anggota-banser-gelarpatroli-di-media-sosial diakses 17 Juli 2017.

http://www.viva.co.id/indepth/sorot/873249-menelisik-ormas-paramiliter diakses 07 Agustus 2017. 